\title{
Board game and simulation doll for pre- and post- operative guidelines: experience report
}

\begin{abstract}
Introduction: surgical procedures can be dealt with in different ways by patients and family members/caregivers. The nursing team has a fundamental and decisive role in reducing the anxieties, fears and uncertainties that affect the patients who need surgical interventions. In this context, ludic resources represent an alternative to promote health.
\end{abstract}

Objective: to report the experience of a nursing student with the use of a board game and a simulation doll for provision of pre- and postoperative guidelines in a Surgical Clinical Unit, during the accomplishment of Curricular Internship.

Methodology: this is an experience report based on the practical experience of a nursing student during the development of ludic activities in the Curricular Internship of the Nursing Undergraduate Course of a Federal University of the South Region of Brazil.

Results and discussion: for the playful activities with the nursing team, a board game was built with questions about pre- and post-operative care. For the patients and relatives/caregivers, dolls with surgical artifacts were used to simulate some situations that could be present in the surgical process. Ten meetings were held with patients and family/caregivers, and four with the nursing team. The nursing team reported not providing the guidelines with frequency and continuity due to the high demand for work in the surgical unit. Patients presented a clearer understanding of the guidelines.

Final considerations: it was possible to promote involvement of the various actors in the proposed actions. Patients and family members/caregivers independently exercised self-care based on the guidelines they received during the activities. The professionals reaffirmed the importance of the pre- and postoperative guidelines and demonstrated their willingness to give continuity to these actions. The student had a perspective of using ludic activities in his future educational practices as a nurse.

Keywords: ludic therapy, health promotion, nursing
Volume 5 Issue I - 2018

\begin{abstract}
Oclaris Lopes Munhoz, Naiane Glaciele da Costa Gonçalvez, Emanuelli Mancio Ferreira da Luz, Gabriela Oliveira,Tânia Solange Bosi de Souza Magnago, Rafaela Andolhe
\end{abstract}

Department of Nursing, Federal University of Santa Maria, Brazil

Correspondence: Oclaris Lopes Munhoz, Department of Nursing, Federal University of Santa Maria, Brazil, Tel +55 5599 6799 013,Email oclaris_munhoz@hotmail.com

Received: October 03, 2017| Published: February 20, 2018

\section{Introduction}

Several factors in the hospital environment contribute to anxiety and fear of patients, requiring a certain ability to cope with and adapt to complex situations. Surgical procedures and the need for hospitalization are examples of difficult moments faced by patients, since they often break the physical and psychological balance of the human being, so that sick patients suffer from anguish and fears. ${ }^{1}$

If not faced by the patient, stress and anxiety can lead to cancellation of the surgical procedure. However, if patients and families receive good preoperative guidance, these feelings/processes can be minimized. In this context, the nursing team plays a fundamental and decisive role in reducing the anxieties, fears and uncertainties that affect patients who need surgical interventions. ${ }^{1,2}$

Surgical clinic nurses, as care managers, should seek alternatives to improve care, with a focus on preventing complications and promoting health. A transformation in the way of managing nursing care is important for this to happen. ${ }^{3}$ The promotion of continuing health education must be present at the different levels of health care, making it possible to empower the professionals working in these services, as well as the patients seeking care. ${ }^{4}$

A study carried out in a public hospital in the West of Santa
Catarina, Brazil, with patients submitted to surgical procedures aimed to describe the perception of surgical patients about the nursing care in the preoperative period, the feelings experienced, as well as the care given by the team of nursing. In this study, the category "knowledge about the surgical procedure" gave evidence that the patients were aware of the procedures that had been submitted, but they did not know how the surgical procedure had been performed.

During the realization of curricular training in hospital care in a surgical clinical unit, it was noticed how important the pre- and postoperative guidance to patients submitted to surgical procedures are. However, it could be noticed that these guidelines are not so often provided and that, when they were given, family members and caregivers were rarely involved. Moreover, the language used to provide these guidelines was, in many cases, basically technical, prompting doubts among patients and family members/caregivers about procedures that had been or would be performed.

In view of this, the following question was raised: what are the most effective strategies for guiding patients in the pre- and postoperative period in a surgical clinic? To answer this question, the literature shows that ludic strategies can be an effective tool in health promotion, because ludic dynamics make, the involved people feel welcome and encouraged to participate in the care. Still, the ludic is 
directly related to feelings of freedom and spontaneity, because this type of activity is considered relaxing, free of pressures or judgments. ${ }^{6}$

Throughout the internship, at various moments, it was observed that the patients had doubts about the surgical procedures, as their relatives/caregivers also did. Many patients were unaware of the reasons for having drains, probes and were receiving the necessary care, which demonstrated the superficiality of the pre- and postoperative guidelines. In turn, the nursing team directs its work process to care and/or administrative activities, leaving educational pre- and postoperative guidelines to patients on the back burner. On the other hand, it was observed that when the nursing team provided these guidelines, patients and their relatives/caregivers showed better coping attitudes with fear and anxiety, making them aware of the procedure to which the patients would be submitted.

Based on this assumption, it was decided to develop a board game and use a simulation doll in a way to involve patients, family member/ caregivers and nursing staff, focusing on pre- and postoperative guidelines. Thus, the purpose of this article is to report the experience of a nursing student in the use of a board game and a simulation doll for pre- and postoperative guidance in a Surgical Clinical Unit, during the accomplishment of curricular internship.

\section{Presentation of the experience}

This is a report based on the practical experience of a nursing student in the development of ludic activities during the Supervised Traineeship II, part of the curricular program of the 8th semester of the Undergraduate Nursing Course of a public Federal University in of the state of Rio Grande do Sul, Brazil.

The experience occurred from March to April 2016, in the scenario of the Surgical Clinical Unit of the university hospital of the education institution to which the student is linked. This hospital has 403 beds for hospitalization of patients, it is a reference center for 1.2 million people, and provides free care as part of the Unified Health System (SUS). This surgical clinical unit has 54 beds and provides assistance to patients in preoperative and postoperative situations in the specialties of traumatology, orthopedics, urology, head and neck surgery, plastic surgery, gastroenterology, proctology, and general surgery, besides a group study on skin lesions.?

The specialties selected for the provision of pre- and postoperative guidelines of the present experience were: general, thoracic, urology and plastic surgeries. The other specialties were not contemplated because they had specific teams for these health education actions. The curricular internship in this unit was developed under the supervision of two nursing assistants and a teacher of the Nursing Department of the Institution of Higher Education.

To start of the systematization of the proposed ludic activities, the academic sought technical-scientific knowledge regarding the surgical procedures of the patients that would participate in the ludic activity. The search was conducted in scientific articles, books, and in the Safe Surgery Protocol, published in 2009 by the Pan American Health Organization.

The actions developed involved, firstly, continuing education with the nursing team, through verbal invitation. After acceptance, an educational board was developed, entitled "Pre- and postoperative Guidelines: Nursing Care" (Figure 1), which had pieces with guidelines to be discussed, with topics such as tracheostomy care, exercises for the prevention of thrombosis, respiratory exercises, pain control, types of surgeries and concepts, all focusing on pre- and postoperative guidelines.

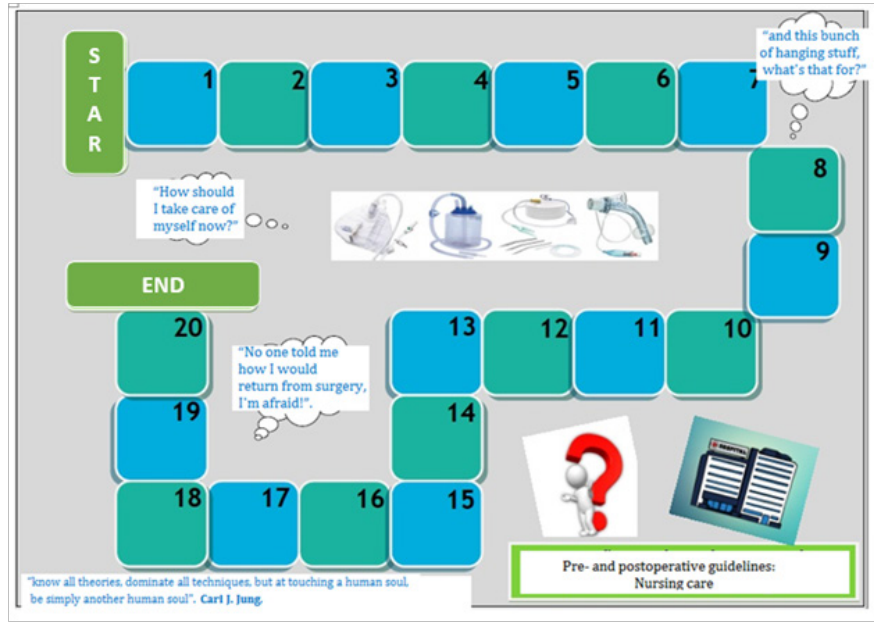

Figure I Pre- and postoperative Guidelines: Nursing Care. Santa Maria, RS Brazil: Springer; 2016.

The goal of the game was to review the guidelines for surgeries as well as to encourage the professionals to later continue developing these actions with patients/family members. The professionals were approached in the interval of the shift and invited to participate in the activity and distributed into two teams, and the goal was "to win the game". Each professional would randomly choose one of the available pieces and play one dice at a time. The resulting number, which varied from one to six, corresponded to the "number of spaces" that the team could "walk on the board". However, the team would score only if it the correct answer was given for the question in the respective piece. Teams would alternate turns. These activities were performed with the nursing teams of the morning shift, corresponding to two meetings with each team lasting approximately 15 minutes.

As for the approach to patients and family members/caregivers, all the information necessary for pre- and postoperative guidance for the surgery to which the patient would be submitted was first searched. Then, patients and families were invited to participate in a conversation where all this information about the surgery was to be presented, in order to clarify their doubts and provide information on the procedures that would be carried out, as well as the necessary care. At that moment, to facilitate the understanding of patients and family members/caregivers, simulation dolls were used (Figure 2). These dolls had probes, dressings, intravenous accesses, drains and catheters that simulated common perioperative therapeutic artifacts, which are materials provided by the unit. These guidelines were given on average twice a week during the internship period and were only delivered after interest and verbal permission from the involved patients and family members/caregivers. The approximate time for each guidance session was 30 minutes. As it was an activity of the curricular internship, there was no need to sign a consent term; the verbal agreement of the patient in participating in the educational action was enough. As this is an experience report and the article does not come from a research project, the opinion of the Research Ethics Committee was not necessary. The information contained in this report does not identify or expose the involved participants, and it was therefore not necessary to use any form or informed consent. 


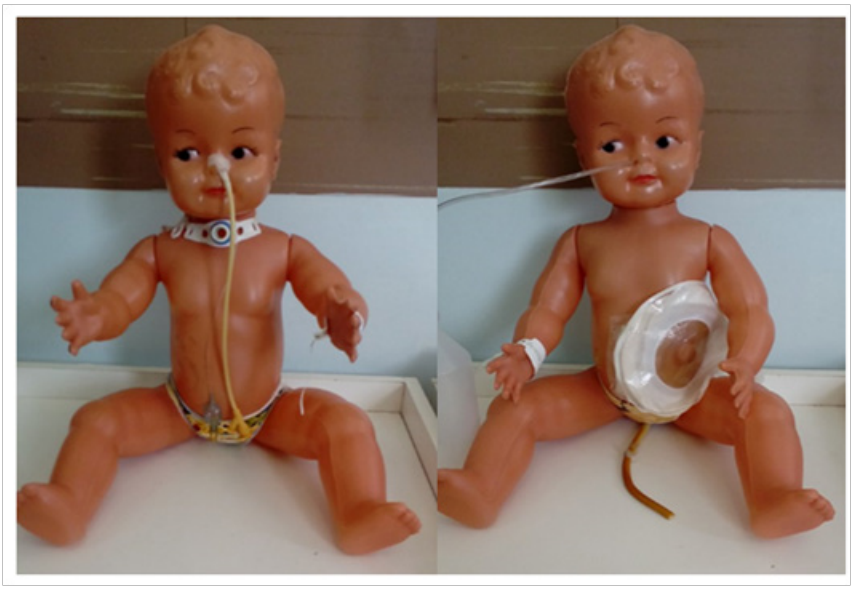

Figure 2 Simulation doll demonstrating surgical artifacts.l

Source: Photographic record of the simulation dolls available in the surgical unit.

\section{Discussion}

During the development of the Supervised Internship, it was possible to carry out the proposed activities, contemplating the main objective of using ludic activities to guide patients, family/caregivers and the nursing staff on pre- and postoperative care in surgical interventions. Approximately ten meetings were held with patients and relatives/caregivers and another four meetings with the nursing team, all in the surgical clinic unit. All had an effective participation.

In the approach to the nursing team, it was noticed that the professionals had knowledge about the pre- and postoperative guidance in most of the specialties. However, they reported that they did not use to carry out the guidelines with frequency and continuity due to the high labor demand in the surgical unit. They highlighted that the time of their shift was often directed to perform routine technical care with patients, undermining health education actions. This is the reality observed in many Brazilian public hospitals due to the lack of adequate staffing and of material resources. ${ }^{8-10}$

With regard to the ludic approach to address pre- and postoperative care, all professionals evaluated this approach positively. They pointed out that the use of the board game made the continuing education on pre- and postoperative guidance more dynamic, easy to understand and enjoyable. Another point highlighted by the team was the time of application of the activity that, according to them, did not interfered in their work flow.

Thus, it is notable that ludic activities contemplate a participatory learning and instigate the interest for a certain theme and, from which it is possible to pursue the transference of knowledge, so that all participants can be active in the teaching-learning process. ${ }^{11}$ The use of ludic activities is important in the process of continuing education of professionals, as well in health education to patients. They are a dialogic method and attract individuals to participate in the process of acquisition and creation of habits for the assimilation, construction and reconstruction of experiences.

In the experience reported here, it was realized how important it was to use it. During the meetings to provide the guidelines to patients and family members/caregivers, several were the moments in which this public was not aware of the procedures to which the patients would be submitted and the necessary care afterwards. On the one hand patients had knowledge about the procedure to which they would be submitted, but they did not know what would come next. On the other hand, relatives and caregivers were apprehensive about not knowing what postoperative care that should be done to help their relatives in the recovery. Feelings such as fear, nervousness, safety and insecurity are identified and experienced in moments of surgical procedures. $^{5}$

A study that sought to describe the perception of surgical patients about the nursing care in the preoperative period showed that all the patients participating in the research were aware of the procedure to which they would be submitted, but in different ways. Some did not know the name of the procedure, others knew the surgical site but could not clearly explain how the surgery would be performed. Another factor highlighted by the study was the difficulty of communication between the nursing team and the patients, in the sense of demonstration of knowledge and valuing of this instrument, essential in the professional-patient relationship. ${ }^{5}$

Moreover, the patients often saw themselves with people and environments that were hitherto unknown, with changes that are the result of the surgical process and, in a way, can generate expectations and anxiety. ${ }^{12}$

Based on the doubts and anxiety that patients and relatives/ caregivers reported in the meetings, the necessary guidelines were prepared to minimize these issues. Before the end of each meeting, all were invited to report on how they were feeling after having received the pre- and postoperative guidelines. Then the patients said they were confident, more prepared for the procedures, and with controlled fear and anxiety. Relatives and caregivers, in turn, also expressed the satisfaction in knowing how they could help their loved ones. All had a feeling of being care actors, exercising autonomy.

The described feelings corroborate another study ${ }^{12}$ that showed a reduction in the level of anxiety and stress in patients who received guidance about the procedures to which they would be submitted. Thus, it is plausible to affirm that the pre-operative nursing visit and guidelines are strategies that should be used by nursing professionals, in the search for the qualification of care and reduction of fears and anxiety of surgical patients. ${ }^{1,12}$

Another facilitator for the understanding of the coming pre- and post-operative procedures and guidelines by patients/caregivers was the use of dolls made available by the unit. The participants reported to be more enlightened about the guidelines, as the dolls simulated the appearance of a body image after surgical interventions, demonstrating each type of venous access, drain, catheter or dressing that could be used. In this context, the ludic activities sought a relaxed but at the same time efficient way to share important information about a given subject. With that, the ludic activity began to be recognized and used for the learning and development of human behavior. ${ }^{13}$

Finally, it is emphasized that the ludic method is an efficient tool in the teaching-learning process, because, besides promoting health education, it promotes immediate personal and emotional satisfaction to participants. These types of educational actions have stood out in the care scenario, since they represent strategies that generate changes in the work environment, contemplating the integral assistance to patients. ${ }^{14}$ In this perspective, the use of ludic activities is efficient for the guidance of health professionals, patients and family members/caregivers, which includes a dialogic education in which the participants improve their knowledge. Furthermore, the educational actions developed in this experiment evidenced that both the board 
game and the dolls can be replicated in other nursing spheres as a positive strategy for care and for the work process.

\section{Final considerations}

This experience had the effective participation of professionals, patients and family members/caregivers, and the student in the actions developed in the surgical unit regarding the pre- and postoperative period. In relation to the patients and family members/caregivers, the guidelines received during the ludic activities gave them the opportunity to exercise self-care with autonomy, since the guidelines exposed through ludic actions also represented a welcome for understanding more clearly, without fear of judgment for expressing doubts.

The nursing team, in turn, reported to feel encouraged to participate in the activities, due to the way the dynamics with the educational game were conducted. According to the professionals, the time of the activity did not interfere in their routine demands in the unit, and endorsed the importance of pre- and postoperative guidelines. They showed to be willing to continue these actions.

To the student, the experience provided knowledge and the perspective of using this tool in his future educational practices as a nurse. It is in this context that the implications for both practice and education in nursing are envisaged. That is, experience showed that playful activities are a strong ally in promoting the autonomy of patients and family members/caregivers as agents of care itself. It is also an ally in the continuing education of health professionals, for their commitment with effective actions, as well as in the training of future professionals, as drivers of changes in the context of the care practice. This favors nursing teaching and practice.

\section{Acknowledgments}

None.

\section{Conflict of interest}

The author declares no conflict of interest.

\section{References}

1. Gonçalves TF, Medeiros VCC. The preoperative visit as the anxiety mitigating factor in surgical patients. Rev SOBECC. 2016;21(1):22-27.
2. Amthauer C, Falk JW. O enfermeiro no cuidado ao paciente cirúrgico no período pré-operatório. Rev de Enf FW. 2014;10(10):54-59.

3. Silva YC, Roquete FF. Responsibilities of manager in health services: analysis of scientific c production in the period 2001 to 2011. RAS 2013;15(58):1-11

4. Borges MCLA, Ponte KMA, Queiroz MVO, et al. Educational practices in hospital environment: reflections on nurses' performance. Rev pesq cuid Fundam. 2012;4(3):2592-2597.

5. Ascari RA, Neiss M, Sartori AA, et al. Perceptions of surgical patient during preoperative period concerning nursing care. Rev enferm UFPE. 2013;7(4):1136-1144.

6. Farias JM, Maggi RM. Estratégia lúdica para a promoção do estilo de vida ativo em usuários do SUS. Revista Saúde e Pesquisa. 2015;8(2):327-334.

7. EBSERH. Hospitais Universitários Federais. Hospital Universitário de Santa Maria-HUSM/UFSM. Dimensionamento de serviços assistenciais e da gerência de ensino e pesquisa. Brasília: Springer; 2017.

8. Organização mundial da saúde. Segundo desafio global para a segurança do paciente: Cirurgias seguras salvam vidas (orientações para cirurgia segura da OMS)/Organização mundial da saúde; tradução de marcela sánchez nilo e irma angélica durán rio de janeiro: organização panamericana da saúde; ministério da saúde; agência nacional de vigilância sanitária; 2009

9. Lorenzini E, Deckmann LR, Silva EF. Dimensionamento de pessoal de enfermagem em centro obstétrico. Rev Enferm UFSM. 2015;5(3):661668

10. Menegueti MG, Nicolussi AC, Scarparo AF, et al. Dimensionamento de pessoal de enfermagem nos serviços hospitalares: revisão integrativa da literatura. Rev Eletr Enf. 2013;15(2):551-563.

11. Coscrato G, Pina JC, Mello DF. Use of recreational activities in health education: Integrative review of literature. Acta Paul Enferm. 2010;23(2):257-263.

12. Sampaio CEP, Ribeiro DA, Marta CB, et al. Determinant factors of the anxiety and mechanisms of coping on general surgical procedures. $J$ Res Fundam Care. 2013;(4):547-555.

13. Rodrigues DA, Sampaio TB, Leça ACMM, et al. Práticas educativas em saúde: o lúdico ensinando saúde para a vida. Rev Ciênc Saúde Nova Esperança. 2015;13(1):84-89.

14. Gurgel SS, Taveira GP, Matias EO, et al. Educational games: didactic resources utilized at teaching health education classes. REME. 2017;21:e1016. 